\title{
Do Bubbles Spill Over? Estimating Financial Bubbles in Emerging Markets*
}

\author{
Ozan Hatipoglu ${ }^{\dagger}$ and Onur Uyar ${ }^{\ddagger}$
}

August 28, 2011

\begin{abstract}
High correlation of stock price indices among a relatively large number of developed and emerging markets indicates that bubbles might spill over from one country to another. To test for such spill-over effects we estimate the bubble component of price changes using a non-linear structural state space model with time-variable parameters. We apply directionality tests to bubbles formed in USA and Turkey. We find that bubbles originating in USA lead to bubbles in Turkey. We provide empirical evidence on bubbles formed during major financial crises of the last two decades in Turkey and the last century in US. Despite the improvement in fundamentals and overall economic performance, we find Turkish asset market is still subject to volatile financial bubbles that might stem from abroad.
\end{abstract}

JEL classification: G12, E44, C32

Keywords: Financial Bubbles, Sigma - Point Kalman Filter, Emerging Markets

*We are grateful to Andreas Billmeier, Deger Eryar, Ahmet Faruk Aysan, David Cobham, and Burak Saltoglu for extremely helpful comments. We would also like to thank seminar participants in Medmeeting 2011 at European University Institute, Izmir Economy University and session participants in the Conference on Turkish Economy held at Bogazici University on December 20th, 2010. Ozan Hatipoglu acknowledges financial support from Scientific and Technical Research Council of Turkey (TUBITAK), Nr. 2219 and Boazici University Research Project BAP Nr. 5455.

${ }^{\dagger}$ Department of Economics and Center for Economics and Econometrics, Bogazici University, Bebek, Istanbul 34342 Turkey. Email: ozan.hatipoglu@boun.edu.tr. Phone:+902123597640

${ }^{\ddagger}$ Department of Economics, Bogazici University, Istanbul, 34342, Turkey. 


\section{Introduction}

A growing literature has been documenting the increasingly frequent co-movements of stock price indices across emerging and developed countries for the last quarter century ${ }^{1}$. Coupled with the fact that fundamentals differ substantially among emerging and developed markets, the finding suggests that high correlation of asset prices might be due to factors that cannot be explained solely by the fundamentals. In this paper, we analyze one such factor, namely, a common bubble. While bubbles are frequently cited as plausible factors explaining the stock price movements within a single market ${ }^{2}$, little attention has been paid to how bubbles originating in one country affect prices in another country.

Our argument is as follows: Since emerging market portfolios are held to a large extent by international investors, positive and negative effects of market sentiments in one country might be transferred to another via portfolio chains. Bubbles might start and collapse on more than one market or any bubble emanating from one country might spill over to another either simultaneously or with a time lag.

To illustrate our point, we first develop an improved methodology to measure bubbles in line with the traditional rational bubbles literature. Next, we determine the directional causality of the bubbles between USA and Turkey as a case in point. The success of our strategy relies on the assumption that we can successfully capture the amount of bubble by our proposed methodology.

Studies that address methodology of testing of rational speculative bubbles are challenging for many reasons ${ }^{3}$. The correct detection of market bubble is a difficult task firstly due to uncertainty about the fundamental value of securities. The stochastic feature of market fundamentals makes the detection of rational bubbles harder. Secondly, the correct specification of the bubble formation is difficult especially if the bubbles depend on the fundamentals. On this note, Gurkaynak (2008) argues that for each time the hypothesis of bubbles is not rejected, there might be some other fundamental process that explain the price volatility. Finally, empirical tests for the existence of rational bubbles can become

\footnotetext{
${ }^{1}$ See Shiller (1989), Scheicher, M. (2001), D'ecclesiaand Costantini(2006) and Bekaert, Hodrick and Zhang (2009).

${ }^{2}$ See Chen, Cheng and Cheng (2009) for a recent study on US.

${ }^{3}$ Partly due to the lack of power of testing procedures, early general specification tests for stock market bubbles do not give exact results. For example, Rappoport and White (1993) and West (1987) reject the null hypothesis of no bubbles, while Dezhbakhsh and Demirguc- Kunt (1990) and Diba and Grossman (1988b) report the opposite results. Flood and Garber (1980), Hamilton and Whiteman (1985) and Hamilton (1986) criticize these bubble tests such that bubbles are observationally in accordance with the regime changes in market fundamentals which cannot be observed by the econometrician. Furthermore, Evans (1991) shows by Monte-Carlo simulations that an important class of rational bubbles cannot be determined by these tests.
} 
very complicated.

In this paper, instead of testing bubbles for statistical significance we let the data speak for itself. We assume the bubbles are unobservable but can be extracted from data optimally by a non-linear filter. We first separate the bubble component of a price change from its fundamental component. To do so, we develop a structural non-linear state space model with endogenous bubble formation and estimate the bubble component using a Sigma-Point Kalman Filter (SGKF). The model we propose is similar to $\mathrm{Wu}(1997)$ in terms of dividend and fundamental process but we allow for an endogenous non-linear bubble formation by letting all the parameters to be time-variable. We show that this specification leads to a more correct estimation of bubble magnitudes. We identify the shape and magnitude of bubble formation during major financial crises and show that SGKF performs better then linear filters in predicting price fluctuations. Finally, having extracted the bubble components in two different countries, namely USA and Turkey, we show a causality link between bubble formations in those countries.

To our best knowledge, there is no theoretical or empirical work on how bubbles emanating from one developed market can cause bubbles in an emerging market. While this paper does not provide a theoretical insight, as to how bubbles might spill over, it points to some empirical evidence that bubbles in one country can spill over to another.

The remainder of the paper is organized as follows: In the next section, we review the relevant literature. In the third section, we introduce the state space setup employed in estimations. We introduce the data used in the study in the fourth section. The filter estimates and the results of the causality tests are reported in the fifth section. Section six concludes.

\section{Related Literature}

There has been a substantial amount of empirical work on rational bubbles since the publication of two original papers by LeRoy and Porter (1981) and Shiller (1981), who independently demonstrate that new information about future dividends or present value of future earnings do not justify the volatility of stock prices. Most of the proposed explanations for the divergence, such as non constant discount factors, noise traders, and fads, fail to account for most of the variation in stock prices. A number of authors (Campbell and Shiller, 1988; Diba and Grossman, 1988a; Timmermann, 1995; Shiller 2000; Nasseh and Strauss, 2003; Koustas and Serletis, 2005; Cunado et al 2005) since then have investigated the rational bubbles in a number of developed markets by investigating the relation of stock prices and 
dividends.

Existing rational bubbles models can be classified into two main classes: models of exogenous bubbles and endogenous bubbles. While the first class of models treats bubbles independently from changes in asset's fundamental value fluctuations ${ }^{4}$, the second class does take into account the impact of changes in fundamentals on the process of bubble formation ${ }^{5}$.The second strand which took start with Froot and Obstfeld (1991) proposes intrinsic bubbles, which depend on fundamentals, are more successful in explaining the divergence between fundamentals and stock prices because they allow shocks to fundamentals to propagate through bubbles.

A major issue within the rational bubble framework is how much the bubble component can explain the variation in stock prices if market fundamentals are themselves subject to persistent shocks. Driffill and Sola (1998) generalize the model of Froot and Obstfeld (1991) by developing a Markov-switching model in which bubbles depend on dividends and dividend process are described by two different states. This paper assumes the bubbles depend on fundamentals as in Froot and Obstfeld (1991), Driffill and Sola(1998) and Van Norden and Schaller (2002)). We let the dividend process subject to regime shifts as in Driffill and Sola (1998) but the regime shifts we propose are continous and bubbles grow non-linearly. Formulations in Driffill and Sola (1998) and Van Norden and Schaller (2002) do not allow for negative bubbles, whereas in this paper bubbles can be negative. In our setup, stocks can be both over- and undervalued. Therefore we do not impose any non-negativity constraint on bubbles. While we do not provide an explicit economic theory of negative bubbles our estimation methodology allows us to detect negative bubble components whenever they exist. Chen, Cheng and Cheng(2009) also derive the bubble component of the price changes while looking at the role of bubbles in the relationship between earnings and stock returns. In their setup bubbles are also always positive.

In this paper, we consider a log-linear approximation to a standard linear stock price determination with rational expectations. The state-space model we propose is similar to $\mathrm{Wu}$ (1997) where the bubble is treated as an unobserved state vector in the state space model. We extend this model by specifying parameters of the bubble and dividend processes as

\footnotetext{
${ }^{4}$ The tests on exogenous bubbles fall in to two categories: variance bounds tests (Shiller (1981), LeRoy and Porter (1981), Campbell and Shiller (1988), West (1987), Cochrane (1992), Dezkbash and DemirgucKunt (1990), Flood and Garber(1994)) and cointegration tests based on long term relationship between stock prices and dividends (Diba and Grossman (1988b)). Subsequent papers propose periodically collapsing exogenous bubbles such as in Hall et al (1999) and Van Norden and Vigfusson (1998)

${ }^{5}$ McQueen and Thorley (1994), Cunadoetal (2005), and Engsted(2006) find evidence for intrinsic rational bubbles whereas the hypothesis of rational bubbles is rejected in Wu (1995), Chan et al (1998),and Koustas and Serletis (2005).
} 
time variables to capture the non-linearity both in bubble formation as well as the dividend process. In our setup, bubbles are stochastic and their growth rates are not constant. Our aim is to capture regime shifts both in fundamental and bubble processes that are more frequent in emerging markets. The modified model is non-linear and represents rational bubbles more accurately as suggested by Santos and Woodford (1997) and Battalio and Schultz (2006).

Driffill and Sola (1998) capture the main problem with bubble literature: The model with no bubbles and non-linear fundamental processes and the model with intrinsic bubbles but linear fundamental process have equal power. While we do not compare our results with a no bubbles model, we find that the intrinsic bubble model with a non-linear fundamental process does a credible job in explaining stock price variations when compared to the model with a linear fundamental process.

Lau et al. (2005) use a Kalman filter estimate bubbles for Taiwan, Singapore, Korea and Malaysia under the classical assumptions. Similar to Balke and Wohar (2009) we try to identify the bubble component in the data instead of testing for its existence. Unlike Balke and Wohar (2009), however, we do not specify an ex ante regime switching model but rather estimate time varying coefficients to capture non-linearity in bubble formation. In our model, bubbles are unobservable and obtained through the unscented Kalman filter.

\section{The Model}

To derive the state-space model we use in estimations we take the following present value model with variable discount rates as a departure point.

$$
e^{-r_{t}}=\frac{E_{t}\left[P_{t+1}+D_{t}\right]}{P_{t}}
$$

where $r_{t}$ is the discount rate, $D_{t}$ is the real dividend per share, $P_{t}$ is the real price of a share at the beginning of period and $E_{t}$ is the expectations operator. This condition forms the basis of most of the studies in the rational bubbles literature. The solution to the above specification includes two terms, the rational bubble component and the fundamental component.

$$
P_{t}=\lim _{s \rightarrow \infty} \exp \left(-\sum_{j=0}^{s} r_{t+j}\right) E_{t} P_{s}+E_{t} \sum_{s=0}^{\infty} \exp \left(-\sum_{j=0}^{s} r_{t+j}\right) D_{t+s}
$$


If the transversality condition holds, i.e. $\lim _{s \rightarrow \infty} \exp \left(-\sum_{j=0}^{s} r_{t+j}\right) E_{t} P_{s}=0$ then the price is determined only by the present value of expected future dividend stream:

$$
P_{t}=E_{t} \sum_{s=0}^{\infty} \exp \left(-\sum_{j=0}^{s} r_{t+j}\right) D_{t+s}
$$

which is referred to as the fundamental solution. The problem with estimating equation (2) is that it can not capture negative bubbles because stock prices can be negative when bubbles are sufficiently negative. Since stocks can be disposed at no cost, negative bubbles in this specification are a priori theoretically ruled out. Moreover, both dividends and prices tend to have unit roots that renders (2) inappropriate for testing deviations of prices from fundamental values. To avoid this problem one can rewrite the model in log-deviations as suggested by Campbell and Shiller(1988). Dividing (1) by $D_{t-1}$ yields

$$
\frac{P_{t}}{D_{t-1}}=\left(\frac{E_{t} P_{t+1}}{D_{t-1}}+\frac{E_{t} D_{t}}{D_{t-1}}\right) e^{r_{t}}
$$

By taking logs and using lowercase letters to denote natural logs for the corresponding uppercase letters, e.g. $\log D_{t}=d_{t}$, one can log-linearize expression (4) around a steady-state constant growth rate for dividends $g=\Delta d_{t+j}$ for $j=0,1,2 \ldots$ and a constant discount rate $r$ to obtain a particular linear solution.

$$
p_{t}^{p}=d_{t-1}-E_{t}\left(\sum_{i=0}^{\infty} e^{-i(r-g)}\left(r-d_{t+i}\right)-h\right.
$$

where $h=\log (\exp (r-g)-1)-(r-g) /(1-\exp (r-g))^{6}$. This is the market fundamental solution where the price growth is determined by future dividend growth. The general solution includes a bubble term, $b_{t}$ :

$$
p_{t}^{g}=d_{t-1}-E_{t}\left(\sum_{i=0}^{\infty} e^{-i(r-g)}\left(r-d_{t+i}\right)-h+b_{t}\right.
$$

where $b_{t}$ satisfies

$$
E_{t}\left(b_{t+1}\right)=e^{t(r-g)} b_{t} \text { for } t=0,1,2 \ldots
$$

The general solution can be written in differences as:

\footnotetext{
${ }^{6}$ Note that finite prices require that discount rates are higher than dividend growth rates.
} 


$$
\Delta p_{t}^{g}=\Delta p_{t}^{p}+\Delta b_{t}
$$

The variables in Equation (8) are differences in logs and should be stationary. Since the bubble component, $\Delta b_{t}$, above is unobservable, we treat it as a state vector and estimate it optimally in a parametric state-space setup. Since both dividends and prices are observable we treat them as measurement vectors. Specifically, we define a dividend and a bubble process both of which are subject to regime shifts and a price equation that serves as a signal process along with the dividend equation. The resulting state-space model is given as follows:

$$
\begin{gathered}
\Delta p_{t}=\Delta d_{t}+F_{t} \Delta Y_{t}+\Delta b_{t} \\
\Delta Y_{t}=A_{t}+\left(C_{t}-I\right) Y_{t-1}+v_{t} \\
\Delta b_{t}=\left(\rho_{t}-1\right) b_{t-1}+\eta_{t}
\end{gathered}
$$

where $F_{t}, A_{t}, C_{t}$ are time variable coefficients which follow a random walk process. $\rho_{t}$ represents the growth rate of the bubble as a function of the difference between the discount rate and the growth rate of the dividends. Moreover,

$$
Y_{t}=\left(d_{t}, d_{t-1}, d_{t-2}, \ldots, d_{t-h+1}\right)^{\prime}
$$

is a h-vector and

$$
C_{t}=\left(\begin{array}{cccccc}
\varphi_{t}^{1} & \varphi_{t}^{2} & \varphi_{t}^{3} & \ldots & \varphi_{t}^{h-1} & \varphi_{t}^{h} \\
1 & 0 & 0 & \ldots & 0 & 0 \\
0 & 1 & 0 & \ldots & 0 & 0 \\
\ldots & \ldots & \ldots & \ldots & \ldots & \ldots \\
0 & 0 & 0 & 0 & 1 & 0
\end{array}\right)
$$

is an hxh matrix, $m=(1,0,0, \ldots, 0)$ is a h-row vector, and $F_{t}=m C_{t}\left(I-C_{t}\right)^{-1}[I-(1-$ $\left.\rho_{t}\right)\left(I-\rho_{t} C_{t}\right)^{-1}$ is also a h-row vector and $\mathrm{I}$ is an $\mathrm{h} \times \mathrm{h}$ identity matrix. Innovations $\eta_{t}$ and $v_{t}$ are assumed to be independent, serially uncorrelated and to have zero mean and finite variance $\sigma_{\eta}^{2}$ and $\sigma_{v}^{2}$, respectively. where $\xi$ is $N(0,0.01)$.

This specification assumes and $\operatorname{ARIMA}(\mathrm{p}, 1,0)$ process the log values of the dividends. In the state space setup we assume that $p=2$, which we obtain by estimating (10) alone using maximum likelihood method for various choices of $p$ after imposing constant parameters in 
Table 1: Initial values for dividend process parameters.

\begin{tabular}{lccc}
\hline \hline Sample & $A_{1,1}$ & $\mathrm{C}_{1,1}$ & $\mathrm{C}_{1,2}$ \\
\hline Turkey & -0.005 & 0.104 & -0.063 \\
USA & 0.001 & 0.828 & -0.102 \\
World & 0.002 & 0.050 & -0.036 \\
\hline \hline
\end{tabular}

$A_{t}$ and $C_{t}{ }^{7}$. These point estimates are used as initial values in the SPKF algorithm and are reported in Table 1.

\section{Data}

The data employed for USA in this paper have been taken from the Shiller's online web page. Real stock prices are the nominal Standard and Poor's (S\&P) 500 indexes, deflated by the Consumer Price Index (CPI). Real dividends are the nominal dividends for the S\&P deflated by the CPI. The data employed for Turkey and for the World has been taken from DataStream database. All data is consolidated on monthly basis.

\section{Results}

\subsection{Efficiency}

In this section we provide a comparison of statistical efficiency between several estimation methods including the Sigma Point Kalman Filter (SPKF) we employ in this paper. SPKF is founded on the intuition of Julier and Uhlmann (2004) that it is easier to approximate a probability distribution than it is to approximate an arbitrary nonlinear function or transformation. SPKF has several advantages over the traditional Extended Kalman Filter that is used for non-linear state space models. Extended Kalman Filter propagates the state distribution through the first order linearization of the nonlinear system. As a result of that the posterior mean and covariance could be corrupted. SPKF uses a deterministic sampling approach so this problem is eliminated naturally. Specifically, SPKF estimates a nonlinear function of a random variable through a linear regression between $\mathrm{n}$ points drawn from the prior distribution of the random variable and it is a derivative free alternative to

\footnotetext{
${ }^{7}$ We use both the Akaike information criterion to determine the optimal lag length.
} 
Table 2: Root mean square error: Comparison with alternative models.

\begin{tabular}{ccccc}
\hline \hline & This Paper & Yangru Wu & Intrinsic Bubbles & Simple Present Value \\
\hline RMSE & 3.98 & 4.33 & 21.83 & 39.97 \\
\hline \hline
\end{tabular}

EKF. Utilizing the state space equation system composed of (9), (10) and (11) and related parameter processes, SPKF results are obtained by a MATLAB algorithm. ${ }^{8}$.

To evaluate the performance of our method, we compare root mean square errors we obtain from estimating previous bubble models using the same US data set. The results are reported in Table 2 and they confirm the efficiency gain obtained by the above specification.

\subsection{Bubble component estimates and some important episodes}

In this section, we provide estimates of bubble components in US and Turkey obtained from the SPKF algorithm. Figure 1, Figure 2 and Figure 3 display the actual stock price indices and the associated bubble percentages of price changes indicated by the fundamentals for United States, Turkey and the World, respectively. Percentage numbers on the right yaxis show how much more prices have changed than implied by changes in fundamentals. In all samples, bubble magnitudes are significantly higher in crisis periods compared to calm periods. For Unites States, Great Depression exhibits the largest financial bubble ever recorded. Within the available sample period, the oil crisis period in the World and the economic crisis of 1994 in Turkey are associated with largest bubbles. Bubble magnitudes in World and US have been decreasing since 1970's with occasional bursts such as the 1987 crisis. Turkish bubbles are significantly more volatile than US and World bubbles during both calm periods and crises. Our results indicate that in Turkey sub-periods of 1993-1995, 1997-1998, 2001-2003 and 2008-2009 periods exhibit extremely volatile bubbles. Unlike US and the World, bubbles in Turkey do not show a tendency to diminish after 1970's.

The fact that there has been an increase in the importance of shareholder value and a higher share of profits have been allocated towards dividend payments particularly after the 1980s, suggest bubbles might be procyclical with and exacerbated by positive dividend shocks. Despite this possibility bubbles show a tendency to decrease in USA. One explanation of why US has been experiencing smaller bubbles over time is that corporate governance and dividend policies have become relatively more transparent in the sense that investors

\footnotetext{
${ }^{8}$ The MATLAB code is available from the authors. The details of the algorithm is given in Appendix.
} 
are better informed in terms of both fundamental valuation and dividend processes. If this is indeed the case, our estimated bubbles are less likely to capture errors stemming from misspecified fundamental processes. While there is no regulation that governs dividend policies of companies, Securities Investor Protection Act of 1970 might have contributed to better investor awareness about companies by regulating how security brokers operate. Secondly, Sarbanes-Oxley Act of 2002 might have played a role in forcing companies to be more transparent about their fundamentals as well as dividend payout schemes.

On the other hand, low market capitalization and relatively secretive dividend policies of publicly traded firms in Turkey might partly explain the high volatility of the bubbles. Since not all cash flows are distributed through the dividend process, bubbles in Turkey might be overestimated.

Our results indicate that as prices reach to both high and low extremes relative to historical averages there is a significant increase in the bubble component. This finding is compatible with the hypothesis that bubbles start small, become progressively bigger and finally burst. It also suggests that negative bubbles occur and mimic the properties of positive bubbles. and Finally, we find that despite the improvement in fundamentals and overall economic performance, Turkish asset market is still subject to volatile bubbles that might stem from abroad.

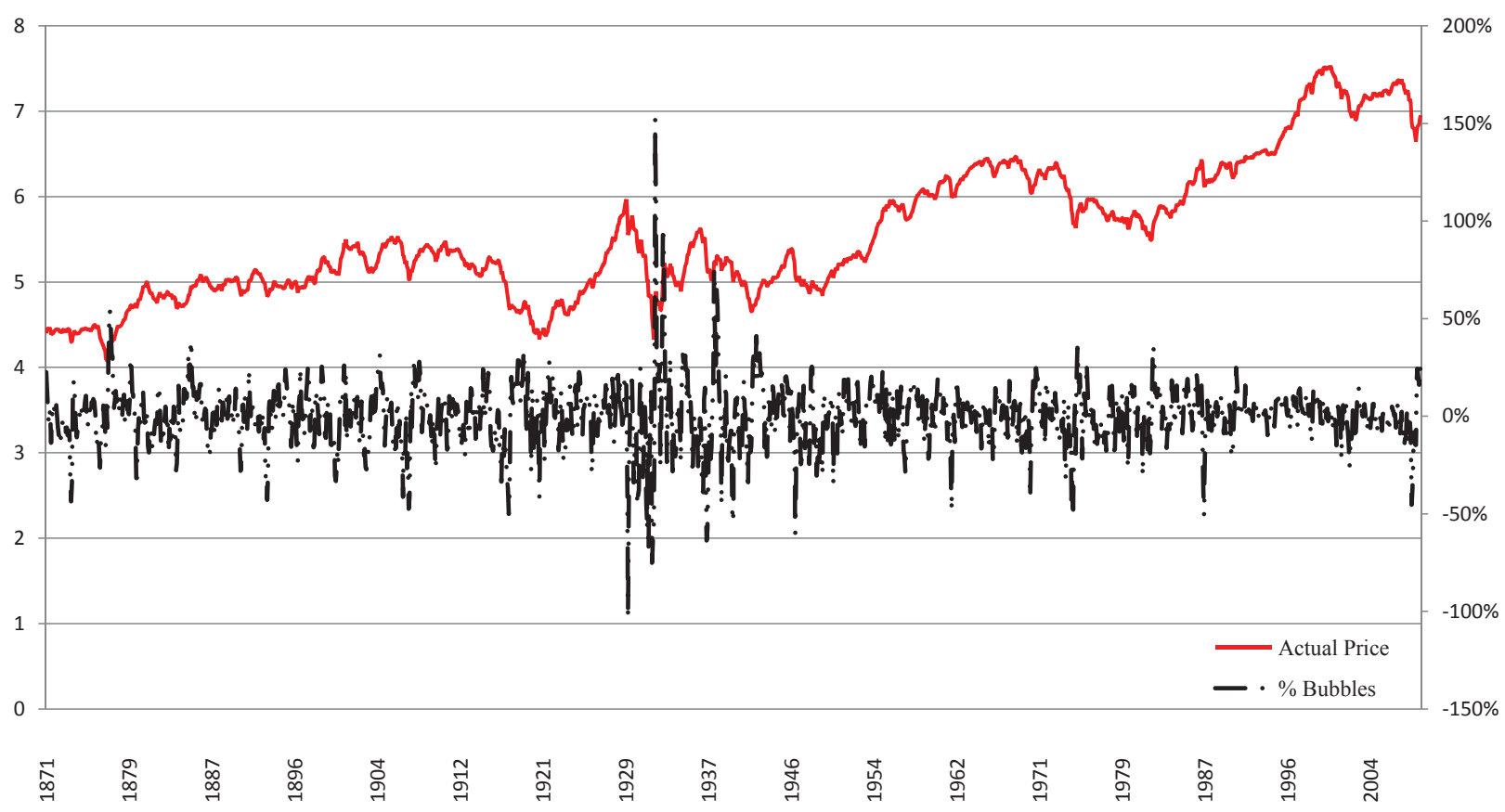

Figure 1: Prices and bubble percentages: USA. 


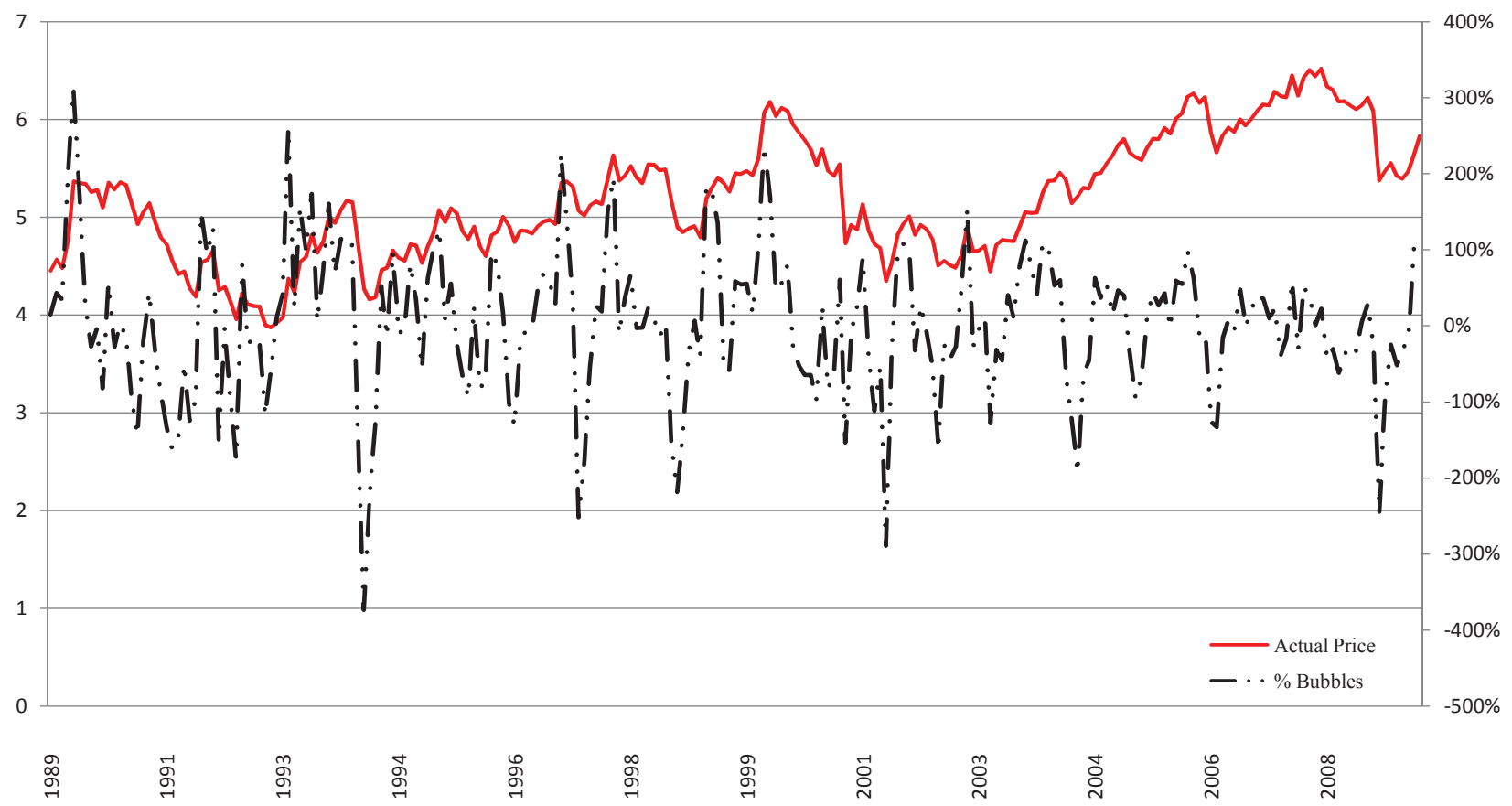

Figure 2: Prices and bubble percentages: Turkey.

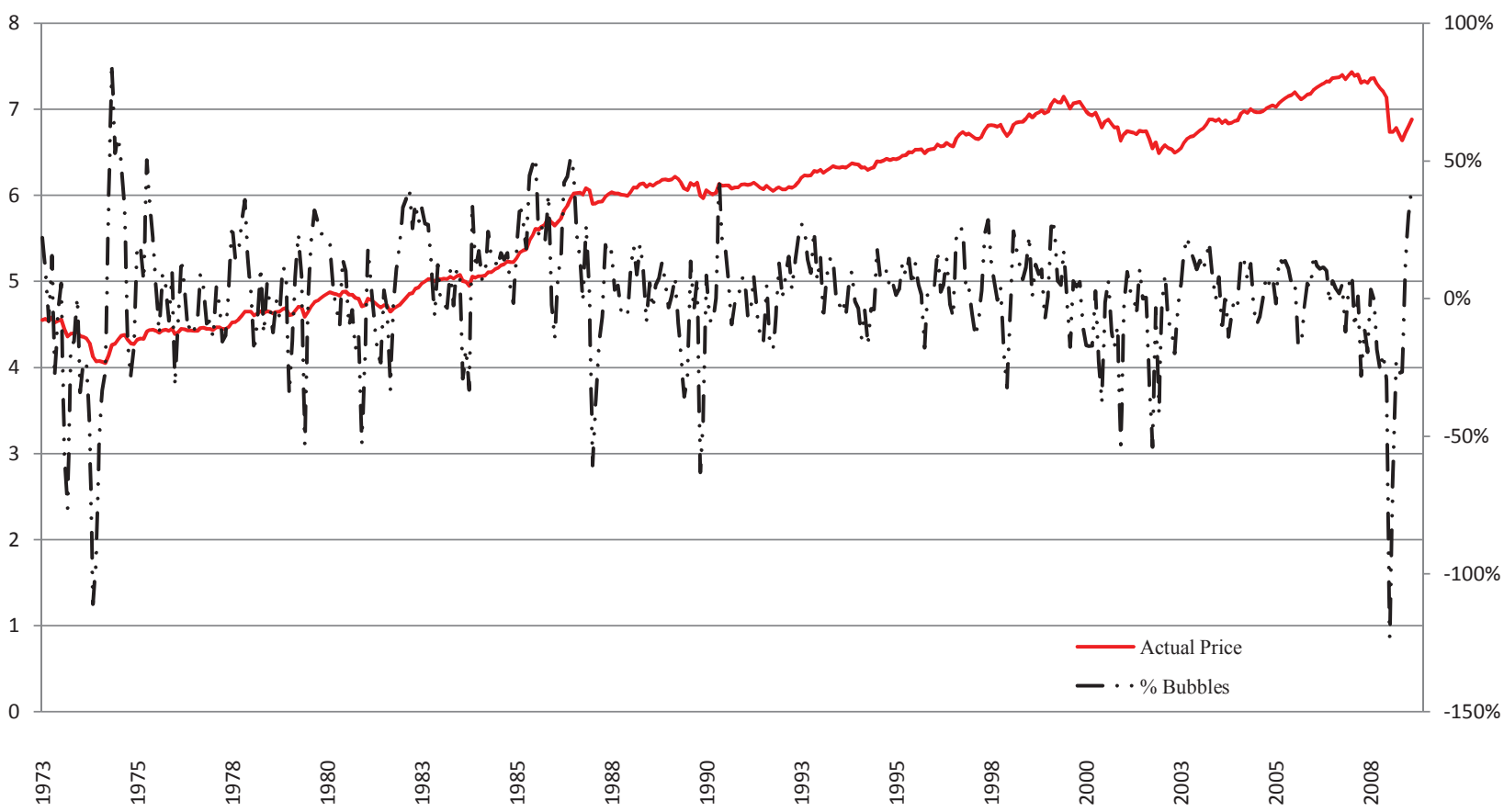

Figure 3: Prices and bubble percentages: World. 

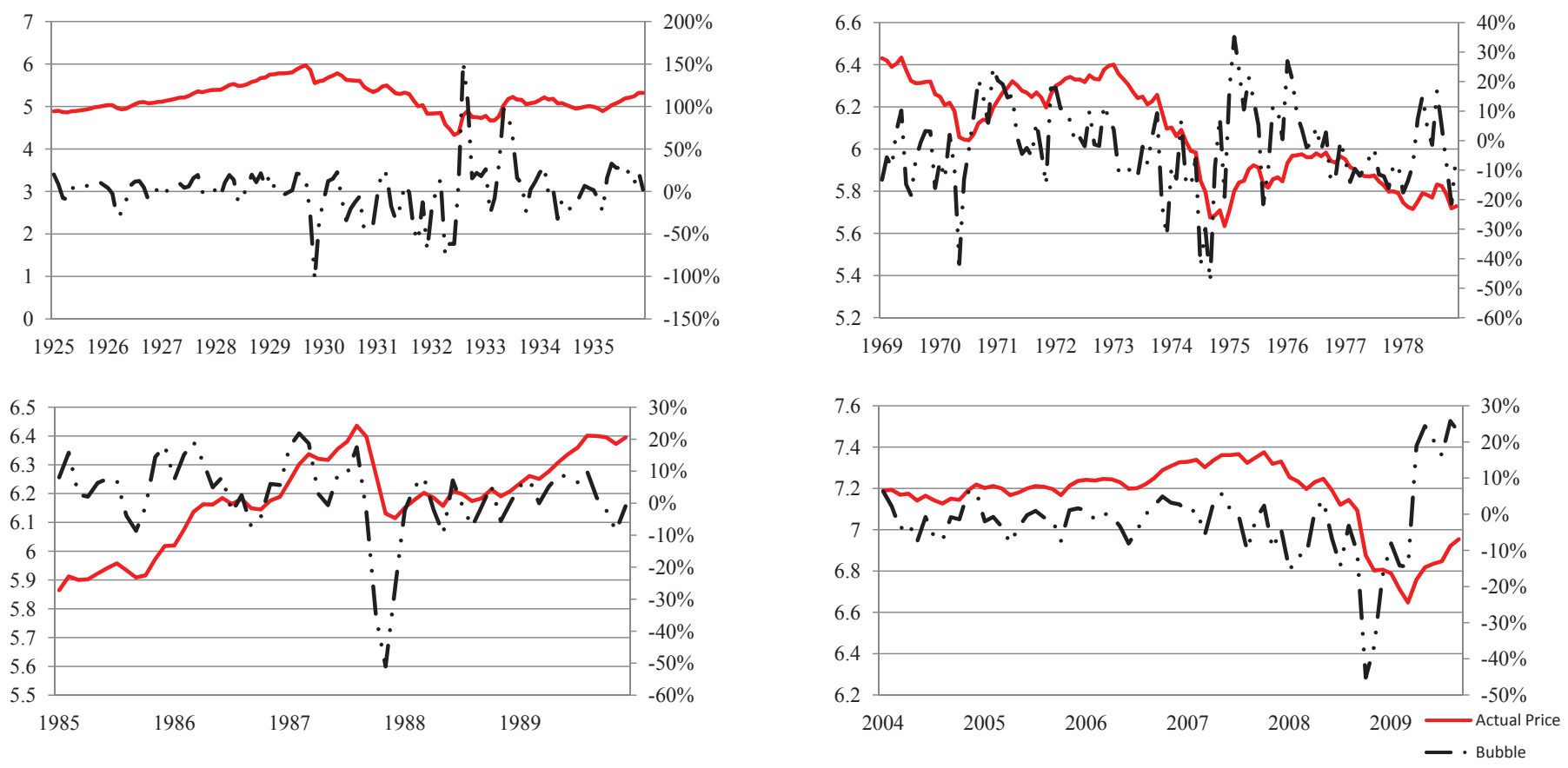

Figure 4: Crises in US.
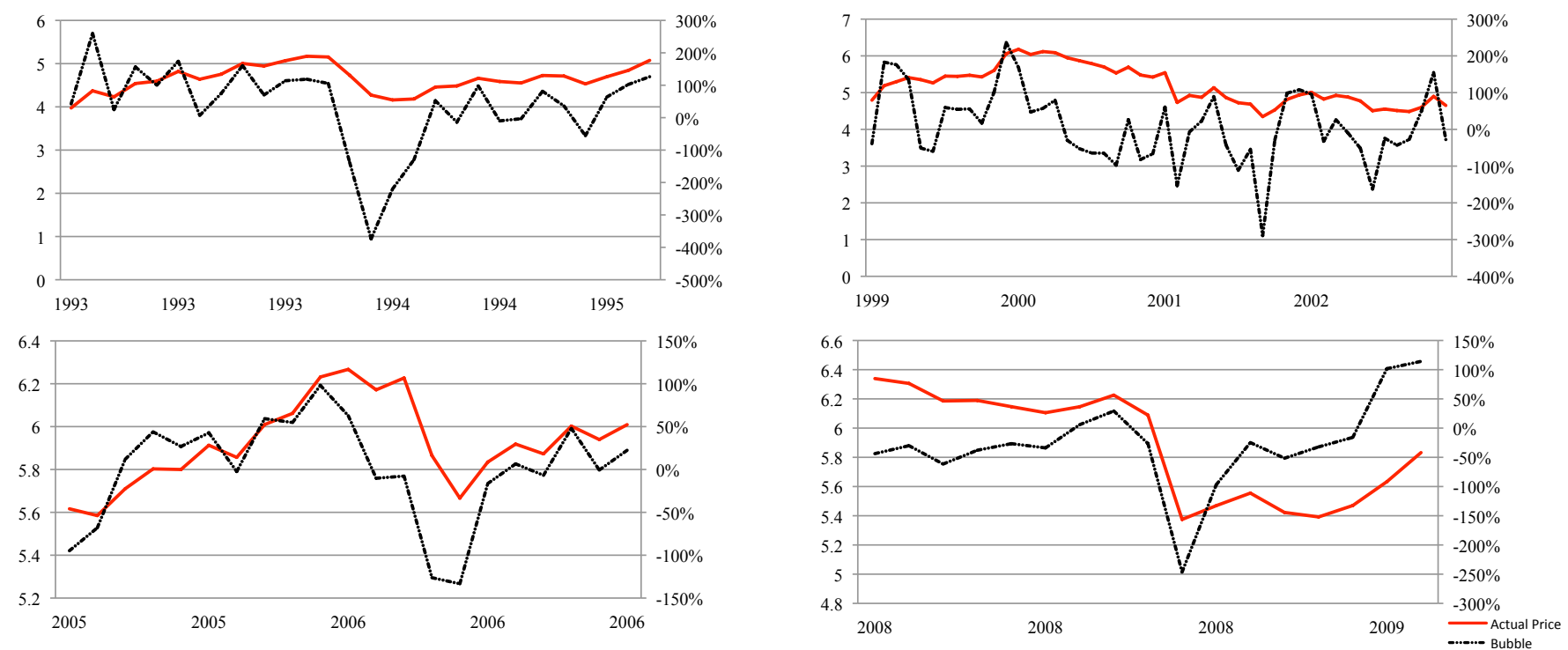

Figure 5: Crises in Turkey. 


\subsection{Granger Causality Tests}

Figure 6. show the co-movements of ISE100 and SP500 for the last two decades where SP500 acts as a trend line for ISE100 for the most part of the sample period. However, there is a clear break after 2004 when ISE starts to outperform SP500 in dollar terms. To further investigate if bubbles in US or World have some explanatory power in predicting bubbles in Turkey we run Granger Causality tests on the estimated bubble series.

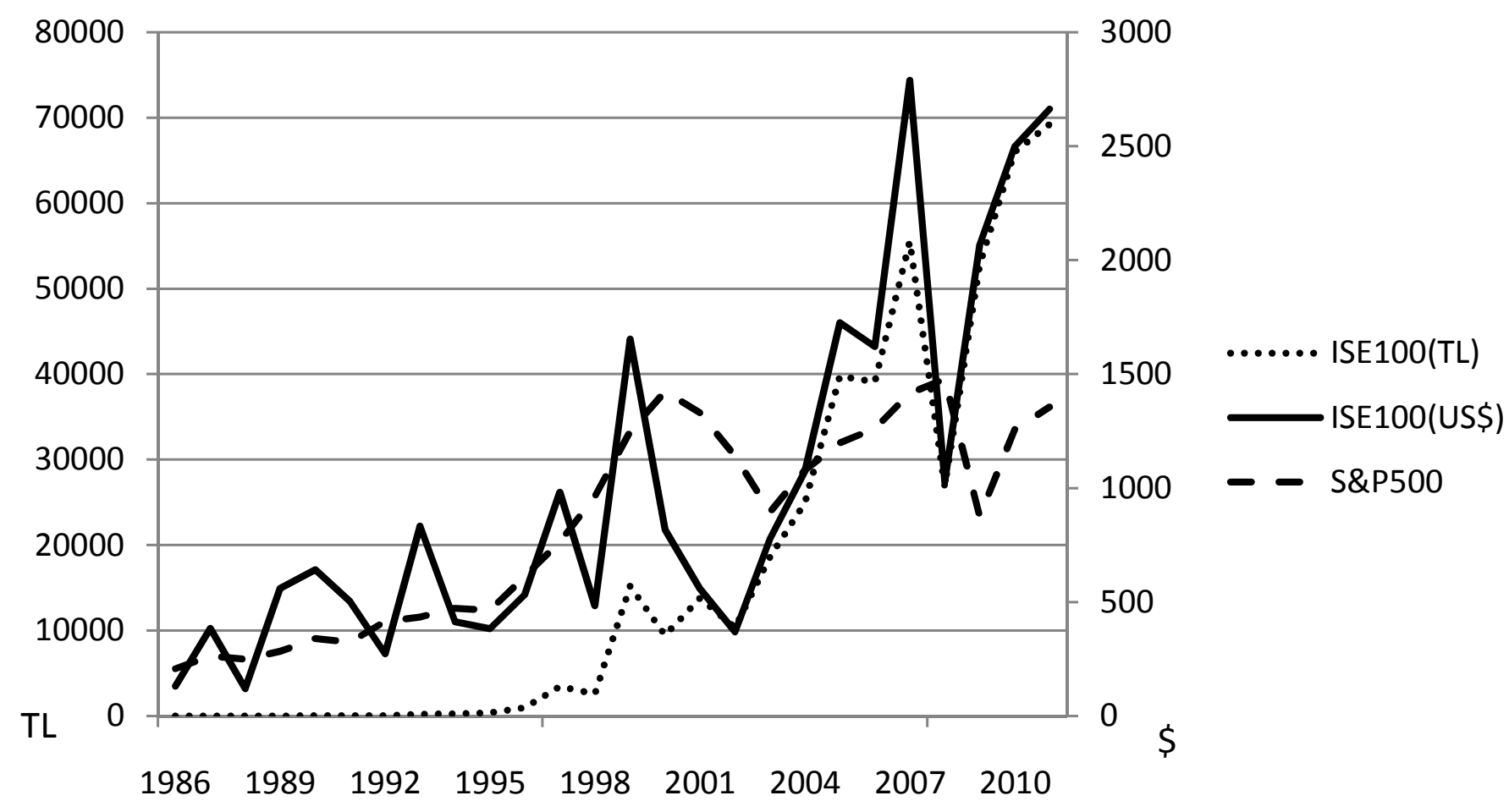

Figure 6: Co-movement of Stock Indices: ISE100 and SP500.

To facilitate the causality tests, we first run ADF tests on bubble data. No unit roots are found in any of the estimated bubble series. Table 3. reports the findings of the linear causality tests. The bubbles originating in US explain bubbles in Turkey with a lag of 10 but fail to cause any changes in bubbles with a lag less than 7, whereas bubbles originating in Turkey does not Granger cause bubbles in US. Similarly, a bubble originating in the world does not Granger cause bubbles in USA except with a lag of 1, but it Granger causes bubbles in Turkey at all lag lengths. 
Table 3: Granger causality tests: p-values.

\begin{tabular}{|c|c|c|c|c|}
\hline Null Hypothesis & Lags: & 10 & 5 & 1 \\
\hline BTR Does Not Granger Cause BUSA & & 0.791 & 0.574 & 0.451 \\
\hline BUSA Does Not Granger Cause BTR & & 0.002 & 0.026 & 0.028 \\
\hline BWORLD Does Not Granger Cause BUSA & & 0.340 & 0.091 & 0.012 \\
\hline BUSA Does Not Granger Cause BWORLD & & 0.091 & 0.187 & 0.031 \\
\hline BWORLD Does $\mathrm{N}$ & & 0.010 & 0.021 & 0.068 \\
\hline BTR Does Not Granger Cause BWORLD & & 0.916 & 0.991 & 0.984 \\
\hline
\end{tabular}

\section{Conclusion}

In this paper, we propose a new estimation method to obtain bubble components of price changes. UKF leads to a more efficient estimation of the nonlinear bubble when compared to similar models. Our findings suggest that bubbles start small, get bigger and collapse most of the time. While bubbles are more pronounced during crises we also find that bubbles get smaller historically with some occasional wild episodes.

On the assumption the bubble process is captured correctly, there is a clear spill-over of bubbles from US to Turkey. Overall, the nonlinear rational stochastic bubble model does a credible job in characterizing the stock markets data. An important caveat with using the rational valuation model in emerging markets is that dividend policy might not reflect all cash flows. If that is indeed the case, then the bubbles in this paper might be overestimated.

The cyclicality of capital movements in emerging markets might be important in determining the magnitude and the nature of the spill-over. If net capital inflows are procyclical, i.e. foreign borrowing increases in good times, this might exacerbate the bubble spill-over effect. In this article, we have not considered such a possibility. But using the bubble data we obtained here, a future exercise might look at the relationship between emerging market countries debt policies and the bubble formation in those countries

A future study might also specify a dividend process, where all cash flows do not filter through dividend payouts. The spillover exercise in this paper can be repeated with European data and other emerging markets. Finally the causality relationship might be revisited by applying non-linear causality tests.

\section{References}

Balke, N. S. and Wohar, M.E. (2009) "Market fundamentals versus rational bubbles in 
stock prices: a Bayesian perspective", Journal of Applied Econometrics, vol. 24, 1, 35-75.

Battalio R. and Schultz P. (2006) "Options and the Bubble", Journal of Finance, 61, 2071-2102.

Bekaert, G., Hodrick R.J. and Zhang Xiaoyan (2009) "International Stock Return Comovements", Journal of Finance, Vol 64, 6, 2591-2626.

Campbell, J.Y. and Shiller, R. J. (1988) "The dividend-price ratio and expectations of future dividends and discount factors", Review of Financial Studies, 1, 195-228.

Chen A.S. , Cheng, L.Y. and Cheng, K.F. (2009) "Intrinsic bubbles and Granger causality in the SP 500: Evidence from long-term data", Journal of Banking and Finance, 33, 2275-2281.

Chan, K., McQueen, G.R. and Thorley, S. (1998) "Are There Rational Speculative Bubbles in Asian Stock Markets?", Pacific-Basin Finance Journal, 6, 125-151.

Cochrane, J. H. (1992) "Explaining the Variance of Price-Dividend Ratios", Review of Financial Studies, 5, 2, 243-80

Cuñado, J., Gil-Alana, L.A. and de Gracia, F. P. (2005) "A test for rational bubbles in the NASDAQ stock index: A fractionally integrated approach", Journal of Banking and Finance, 29, 2633-2654.

D'ecclesia, R.L. and Costantini M. (2006) "Comovements and Correlations in International Stock Markets", The European Journal of Finance,12, 6, 567-582.

Dezhbakhsh, H. and Demirguc-Kunt, A. (1990) "On the Presence of Speculative Bubbles in Stock Prices", Journal of Financial and Quantitative Analysis", 25, 101-112.

Diba, B.T. and Grossman, H.I. (1988a) "Explosive Rational Bubbles in Stock Prices?", American Economic Review, 78, 520-530.

- (1988b) "The Theory of Rational Bubbles in Stock Prices", Economic Journal, $98,3,746-754$.

Driffill, J. and Sola, M. (1998) "Intrinsic bubbles and regime-switching", Journal of Monetary Economics, 42, 2, 357-373.

Engsted, T. (2006) "Explosive bubbles in the co integrated VAR model", Finance Research Letters, 3, 154-162.

Evans, G.W. (1991) "Pitfalls in testing for explosive bubbles in asset prices" American Economic Review, 81, 922-930.

Flood, R.P., and P.M. Garber (1980) "Market Fundamentals vs. Price Level Bubbles: The First Tests" Journal of Political Economy 88, 745-770.

—, eds., (1994), Speculative Bubbles, Speculative Attacks, and. Policy Switching, MIT Press, Cambridge (Mass.) 
Froot, K. A. and Obstfeld, M. (1991) "Intrinsic Bubbles: The Case of Stock Prices", American Economic Review, American Economic Association, 81,5, 1189-214.

Gurkaynak, R. S. (2008) "Econometric Tests of Asset Price Bubbles. Taking Stock", Journal of Economic Surveys, 22, 166-186.

Hall, S.H., Psaradakis, Z. and Sola, M. (1999) "Detecting Periodically Collapsing Bubbles: A Markov-Switching Unit Root Test", Journal of Applied Econometrics, 14, 2, 143-54.

Hamilton, J. D. (1986) "On Testing for Self-Fulfilling Speculative Price Bubbles", International Economic Review, 27,4, 545-552.

Hamilton, J. D. and Whiteman,C.H. (1985) "The Observable Implications of Self Fulfilling Prophecies", Journal of Monetary Economics, 16, 353-373.

Julier, S. and Uhlmann, J. (2004) "Unscented Kalman Filtering and Nonlinear Estimation", Proceedings of the IEEE, 92, 3, 401-422.

Koustas, Z. and Serletis, A. (2005) "Rational bubbles or persistent deviations from market fundamentals?", Journal of Banking and Finance, 29, 2523-39.

Lau, E.L., Tan, G.K.R. and Rahman, S. (2005) "Assessing Pre-Crisis Fundamentals in Selected Asian Stock Markets", The Singapore Economic Review, 50, 02, 175-196.

LeRoy, S.F., and Porter,R.D. (1981) "The Present-Value Relation: Tests Based on Implied Variance Bounds", Econometrica, 49, 555-577.

McQueen, G. R. and Thorley, S. (1994) "Bubbles, Stock Returns, and Duration Dependence", Journal of Financial and Quantitative Analysis, 29, 379-401.

Nasseh, A. and Strauss, J. (2004) "Stock Prices and the Dividend Discount Model: Did their Relationship break down in the 1990s?", The Quarterly Review of Economics and Finance, 44, 2, 191-207.

Pesaran, M. H., and Timmermann, A. (1995) "Predictability of Stock Returns: Robustness and Economic Significance", Journal of Finance, 50, 1201- 1228.

Rappoport, P. and White, E. N. (1993) "Was There a Bubble in the 1929 Stock Market?", Journal of Economic History, 53, 3, 549-574.

Santos M. S. and Woodford M. (1997) "Rational Asset Pricing Bubbles", Econometrica, $65,1,19-58$.

Scheicher, M. (2001) "The Co-movements of Stock Markets in Hungary, Poland and the Czech Republic", International Journal of Finance and Economics, 6, 27-39.

Shiller, R. J. (1981) "Do Stock Price Move too Much to be Justified by Subsequent Changes in Dividends?", American Economic Review, 71, 421-436.

(1989) "Comovements in Stock Prices and Comovements in Dividends", The Journal of Finance, 44, 3, 719-729. 


\section{(2000), Irrational Exuberance, Princeton University Press, Princeton, N.J.}

Timmermann, A. (1995) "Co-integration tests of present value models with a time varying discount factor", Journal of Applied Econometrics, 10, 17-31.

Van Norden, S. and Schaller, H. (2002) "Fads or bubbles?", Empirical Economics,27, 2, 335-362.

Van Norden, S. and Vigfusson, R. (1998) "Avoiding the Pitfalls: Can Regime-Switching Tests Reliably Detect Bubbles?", Studies in Nonlinear Dynamics and Econometrics, 3, 1, Article 1.

West, K.D. (1987) "A Specification Test for Speculative Bubbles", The Quarterly Journal of Economics, 3, 553-580.

Wu, Yangru (1995) "Are there rational bubbles in foreign exchange markets? Evidence from an alternative test", Journal of International Money and Finance,14,1, 27-46.

Wu, Yangru (1997) "Rational Bubbles in the Stock Market: Accounting for the U.S. Stock-Price Volatility", Economic Inquiry, 35, 2, 309-19.

\section{APPENDIX}

\section{A State Space Representation of the Model}

In this appendix, we introduce the state-space representation of the model with relevant coefficient matrices. The model we propose is as follows:

$$
\begin{gathered}
\Delta p_{t}=\Delta d_{t}+F_{t} \Delta Y_{t}+\Delta b_{t} \\
\Delta Y_{t}=A_{t}+\left(C_{t}-I\right) Y_{t-1}+v_{t} \\
\Delta b_{t}=\left(\rho_{t}-1\right) b_{t-1}+\eta_{t}
\end{gathered}
$$

To facilitate the filter one has to transform the above model into the following state space representation :

$$
\begin{gathered}
x_{k+1}=f\left(x_{k}, u_{k}, t_{k}\right)+\omega_{k} \\
y_{k}=h\left(x_{k}, t_{k}\right)+v_{k}
\end{gathered}
$$

where $f(\cdot)$ is non-linear function of the state variables, $x_{k}$, control or signal variables, $u_{k}$ 
and exogenous variables $t_{k} . \omega_{k}$ and $v_{k}$ are i.i.d shocks with zero mean and covariance matrices $Q_{k}$ and $R_{k}$, respectively. To initiate convergence experiments of the covariance matrices, the initial values of $Q_{k}$ and $R_{k}$, denoted respectively as respectively $Q_{0}$ and $R_{0}$, are assumed to be equal to the linear filter residual covariance matrices. To obtain the initial values for the linear filter residual covariance matrices we implement the autocovariance least-square method which is available as a standart package in MATLAB.

$$
\begin{gathered}
p_{t}=F_{t} A_{t}+p_{t-1}+\left(\rho_{t}+1\right) \cdot b_{t}+\left[F_{t}\left(C_{t}-I\right)\right] \cdot Y_{t-1}+\Delta d_{t} \\
Y_{t}=A_{t}+C_{t} Y_{t-1}+v_{t}=\left(\begin{array}{c}
u \\
0
\end{array}\right)+\left(\begin{array}{cc}
h_{1, t} & h_{2, t} \\
1 & 0
\end{array}\right) \cdot\left(\begin{array}{c}
\Delta d_{t-1} \\
\Delta d_{t-2}
\end{array}\right)+\left(\begin{array}{c}
\delta_{t} \\
0
\end{array}\right) \\
\Delta b_{t}=\left(\rho_{t}-1\right) \cdot b_{t-1}+\eta_{t} \\
C_{t}=C_{t-1}+\kappa_{1, t}
\end{gathered}
$$

We define the state vector as

$$
x_{k}=\left(\begin{array}{c}
b_{k} \\
p_{k} \\
Y_{k}
\end{array}\right),
$$

which can be summarized in the following non-linear function

$$
\begin{aligned}
& f\left(x_{k}, u_{k}, t_{k}\right)=\alpha \cdot x_{k-1}+\beta . u_{k} \\
& \text { Where } \\
& \alpha=\left(\begin{array}{ccc}
\rho_{t} & 0 & 0 \\
\rho_{t}+1 & 0 & F_{t}\left(C_{t}-I\right) \\
0 & 0 & C_{t}
\end{array}\right) \\
& \beta=\left(\begin{array}{lll}
0 & 0 & 0 \\
0 & 1 & 0 \\
0 & 0 & 1
\end{array}\right) \\
& \varepsilon=\left(\begin{array}{c}
\eta_{k} \\
F_{t} v_{k}+\eta_{k} \\
v_{k}
\end{array}\right)
\end{aligned}
$$




$$
\begin{aligned}
& h\left(x_{k}, t_{k}\right)=H . x_{k} \\
& \text { where } \\
& H=I,
\end{aligned}
$$

\section{B Sigma-Point Kalman Filter Algorithm}

The filter is implemented via the following algorithm where plus $(+)$ sign denotes the posterior and minus $(-)$ sign denotes the prior estimate and the approximate sign $(\approx)$ denotes the current estimate.

$$
\begin{aligned}
& x_{k+1}=f\left(x_{k}, u_{k}, t_{k}\right)+\omega_{k} \\
& y_{k}=h\left(x_{k}, t_{k}\right)+v_{k} \\
& \omega_{k} \sim\left(0, Q_{k}\right) \\
& v_{k} \sim\left(0, R_{k}\right)
\end{aligned}
$$

1-Initiation

$$
\begin{aligned}
& \hat{x}_{o}^{+}=E\left(x_{o}\right) \\
& P_{o}^{+}=E\left[\left(x_{o}-\underset{o}{\hat{x}^{+}}\right) \cdot\left(x_{o}-\underset{o}{\hat{x}^{+}}\right)^{T}\right]
\end{aligned}
$$

2- Sigma Point Estimator and Prediction Phase

$$
\begin{aligned}
& \hat{x}_{k-1}^{(i)}=\hat{x}_{k-1}{ }^{(i)}+\widetilde{\widetilde{x}}^{(i)}, i=1, \ldots, 2 n \\
& \widetilde{\widetilde{x}}^{(i)}=\left(\sqrt{n \cdot P_{k-1}^{+}}\right)_{i}^{T}, i=1, \ldots, n \\
& \widetilde{\widetilde{x}}^{(n+i)}=-\left(\sqrt{n \cdot P_{k-1}^{+}}\right)_{i}^{T}, i=1, \ldots, n \\
& \hat{x}^{(i)}=f\left(\stackrel{\hat{x}}{x-1}^{(i)}, u_{k}, t_{k}\right) \\
& \hat{x}^{-}=\frac{1}{2 n} \sum_{i=1}^{2 n}{\underset{k}{x}}^{(i)}
\end{aligned}
$$

and

$$
P_{k}^{-}=\frac{1}{2 n} \sum_{i=1}^{2 n}\left(\begin{array}{l}
\hat{x}_{k}^{(i)}-\hat{x}_{k}^{-} \\
{ }_{k}
\end{array}\right) \cdot\left(\begin{array}{l}
\hat{x}_{k}^{(i)}-\hat{x}_{k}^{-} \\
{ }^{(}
\end{array}\right)^{T}+Q_{k-1}
$$

3-Sigma Point Estimator and Measure Phase 


$$
\begin{aligned}
& \hat{x}_{k}^{(i)}=\hat{x}^{-}+\widetilde{\widetilde{x}}^{(i)}, i=1, \ldots, 2 n \\
& \widetilde{\widetilde{x}}^{(i)}=\left(\sqrt{n \cdot P_{k}^{-}}\right)_{i}^{T}, i=1, \ldots, n \\
& \widetilde{\widetilde{x}}^{(n+i)}=-\left(\sqrt{n \cdot P_{k}^{-}}\right)_{i}^{T}, i=1, \ldots, n \\
& \hat{y}^{(i)}=h\left(\hat{x}_{k}^{(i)}, t_{k}\right) \\
& \hat{\hat{y}}=\frac{1}{2 n} \sum_{i=1}^{2 n} \hat{y}_{k}^{(i)}
\end{aligned}
$$

where the covariance matrix is given by

$$
\left.P_{y}=\frac{1}{2} \sum_{i=1}^{2 n}\left(\begin{array}{l}
\hat{y}(i) \\
k
\end{array}-\underset{k}{\hat{y}}\right) \cdot\left(\begin{array}{l}
\hat{y}(i) \\
k
\end{array}\right) \stackrel{\hat{y}}{k}\right)^{T}+R_{k}
$$

and

$$
P_{x y}=\frac{1}{2 n} \sum_{i=1}^{2 n}\left(\begin{array}{l}
\hat{x}_{k}^{(i)}-\hat{x}_{k}^{-} \\
k^{-}
\end{array}\right) \cdot\left(\begin{array}{l}
\hat{y}_{k}^{(i)}-\underset{k}{y} \\
{ }^{(i)}
\end{array}\right)^{T}
$$

The posterior estimates are updated as follows:

$$
\begin{aligned}
& K_{k}=P_{x y} \cdot P_{y}^{-1} \\
& \hat{x}_{k}^{+}=\hat{x}_{k}^{-}+K_{k} \cdot\left(y_{k}-\underset{k}{\hat{y}}\right) \\
& P_{k}^{+}=P_{k}^{-}-K_{k} \cdot P_{y} \cdot K_{k}^{T}
\end{aligned}
$$

